\title{
A BIODEMOCRACIA E OS DIREITOS DA SOCIOBIODIVERSIDADE: (RE) EXISTÊNCIAS E (CO) EXISTÊNCIAS DOS POVOS E COMUNIDADES TRADICIONAIS
}

\section{Juliete Prado de Faria* Maria Cristina Vidotte Blanco Tárrega*}

\section{RESUMO}

Este artigo trata dos direitos da sociobiodiversidade na perspectiva da biodemocracia, com enfoque nos Povos e Comunidades Tradicionais. Esse tema está presente nos debates da atualidade, devido a constante violação dos direitos desses povos e comunidades. O objetivo é estabelecer o potencial da biodemocracia para a efetivação dos direitos da sociobiodiversidade. $\mathrm{O}$ método utilizado é o de revisão bibliográfica, na perspectiva do materialismo histórico. Levanta-se que a biodemocracia pode ser uma alternativa para a garantia dos direitos da sociobiodiversidade, sendo mecanismo de (re) existência e (co) existência.

Palavras-chave: Biodemocracia; Sociobiodiversidade; Povos e Comunidades Tradicionais; Socioambientalismo; Direitos.

\section{BIODEMOCRACY AND THE RIGHTS OF SOCIOBIODIVERSITY: (RE) EXISTENCE AND (CO) EXISTENCE OF TRADITIONAL PEOPLES AND COMMUNITIES}

\begin{abstract}
This article deals with the rights of socio-biodiversity in the perspective of biodemocracy, with a focus on Traditional Peoples and Communities. This theme is present in the debates of the present day, due to the constant violation of the rights of these peoples and communities. The objective is to establish the potential of biodemocracy for the realization of sociobiodiversity rights. The method used is that of bibliographical revision, in the perspective of historical materialism. It emerges that biodemocracy can be an alternative to guarantee the rights of socio-biodiversity, being a mechanism of (re) existence and (co) existence.
\end{abstract}

Keywords: Biodemocracy; Sociobiodiversidade; Traditional Peoples and Communities; Socioenvironmentalism; Rights.

\section{INTRODUÇÃO}

Segundo o Relatório de Monitoramento da Cobertura do Solo e Uso da Terra, elaborado pelo Instituto Brasileiro de Geografia e Estatística (IBGE), o Brasil perdeu 7,5 por cento de sua vegetação florestal entre os anos 2000 e 2016 (BRASIL, 2016). 
Conforme apontado no Relatório, o estudo demonstra que as alterações na vegetação florestal do país têm relação direta com os fatores socioeconômicos, históricos e culturais. $\mathrm{O}$ avanço das fronteiras agrícolas sobre as coberturas de vegetação e a crescente complexidade das redes de transporte e comunicação tem sido a causa expressiva de mudanças climáticas, alteração do nível do mar, na camada de ozônio, na perda da biodiversidade, poluição do ar, da água e dos solos, erosão, desertificação, entre outros problemas ambientais (BRASIL, 2016).

Por outro lado, os Povos e Comunidades Tradicionais têm papel fundamental na conservação da biodiversidade, sobretudo porque para eles a Terra é sagrada, pensamento este praticamente ausente no pensamento hegemônico eurocêntrico.

A biodiversidade ou diversidade biológica contempla três elementos: a diversidade de espécies da fauna, flora e micro-organismos, diversidade dos ecossistemas e diversidade genética. Somando-se a este conceito o conhecimento, saber ou memória coletiva dos Povos e Comunidades Tradicionais, temos a sociobiodiversidade (BERTOLDI; BARON, 2014).

No entanto, os direitos dos Povos e Comunidades Tradicionais vêm sendo amplamente desrespeitados pelo Estado e pela sociedade brasileiros, como por exemplo na construção de grandes empreendimentos capitalistas em seus territórios, mineração e outras formas de "invasão" do espaço territorial a eles pertencente.

Nesse cenário, a biodemocracia é um modelo de "democracia ecológica", que considera todos os seres vivos na construção de um novo paradigma de conservação da biodiversidade que considere os Povos e Comunidades Tradicionais.

Diante disso, surge a seguinte indagação: a biodemocracia pode ser meio de efetivação dos direitos da sociobiodiversidade dos Povos e Comunidades Tradicionais? Esse mecanismo é alternativa à (re) existência e (co) existência desses povos?

A partir daí, levanta-se a hipótese de que a biodemocracia tem potencial para garantir os direitos da sociobiodiversidade e pode ser uma alternativa na luta pela (re) existência e (co) existência dos Povos e Comunidades Tradicionais, sobretudo devido a sua ótica de leitura da realidade social a partir de uma democracia ecológica e consideração de todos os seres vivos em sua singularidade.

O objetivo geral dessa pesquisa é estabelecer o potencial da biodemocracia como garantidora dos direitos da sociobiodiversidade e como mecanismo de (re) existência e (co) existência dos Povos e Comunidades Tradicionais. 
Como objetivos específicos, pretende-se: a) analisar o conceito e evolução da sociobiodiversidade; b) estudar o conceito de biodemocracia e sua relação com os direitos da sociobiodiversidade; c) verificar quem são os Povos e Comunidades Tradicionais; d) compreender os direitos e desafios enfrentados pelos Povos e Comunidades Tradicionais frente ao modelo de Estado capitalista hegemônico; e) analisar a relação entre os Povos e Comunidades Tradicionais e a biodiversidade.

O método utilizado é o de revisão bibliográfica, na perspectiva do materialismo histórico. A ótica de análise e reflexão utilizada é o olhar crítico da realidade social, fazendo uso do raciocínio dialético marxista (GUSTIN; DIAS, 2010).

\section{SOCIOBIODIVERSIDADE: CONCEITO E EVOLUÇÃO}

Para a compreensão do termo "sociobiodiversidade", inicialmente é necessário fazer alguns apontamentos sobre acontecimentos históricos internacionais e nacionais que foram importantes para o desenvolvimento desse conceito.

No âmbito internacional, entre as décadas de 1960 e 1980, percebe-se uma preocupação dos cientistas, movimentos sociais, ambientalistas e outros setores em relação aos problemas ecológicos e sociais causados pela "Revolução Industrial" e com os efeitos negativos do modelo industrial para o meio-ambiente (VIEIRA, 2012).

Nesse sentido, a Organização das Nações Unidas (ONU) iniciou um ciclo de conferências e estudos com o escopo de planejar estratégias para um desenvolvimento mais inclusivo e harmônico com a natureza, sendo a mais relevante delas a Conferência de Estocolmo, na Suécia, realizada em 1972 (VIEIRA, 2012).

Nessa Conferência, pela primeira vez se associou de forma consistente questões ambientais ao desenvolvimento sustentável na pauta internacional. E também foi um marco na crítica ao modelo de desenvolvimento econômico do sistema capitalista, com ênfase na importância da manutenção da biodiversidade (VIEIRA, 2012).

Portanto, além da Conferência de Estocolmo, também aconteceram outros fatos importantes a respeito da proteção da biodiversidade, como a proposição do Programa das Nações Unidas para o Meio Ambiente (PNUMA), em 1973, que definiu essa proteção como prioridade (BERTOLDI; BARON, 2014). 
No ano de 1987, outro marco da tentativa de se criar instrumentos globais de proteção a biodiversidade foi o Relatório Brundtland, também chamado de "Nosso Futuro Comum", fruto do trabalho de uma comissão da Assembleia Geral das Nações Unidas (BERTOLDI; BARON, 2014).

Daí se nota a preocupação com o equilíbrio entre a natureza, a economia e a sociedade, com uma abordagem mais ampla a respeito da conservação da biodiversidade na tentativa de alcançar a proteção ambiental integralmente para garantir a multiplicidade dos genes, ecossistemas, espécies e valores culturais que compõem a sociobiodiversidade (BERTOLDI; BARON, 2014).

É claro que todas essas Convenção são muito teóricas e não expressam a prática efetiva da maioria dos países que as aderem.

No Brasil, com a promulgação da Constituição Federal de 1988, estabeleceu-se a proteção da sociobiodiversidade, sobretudo no artigo 216, no qual considera-se patrimônio cultural brasileiro os bens de natureza material e imaterial, tomados individualmente ou em conjunto, portadores de referência à identidade, à ação, à memória dos diferentes grupos formadores da sociedade brasileira (BRASIL, 1988). Tal Constituição também dedica capítulo específico a proteção do meio ambiente (capítulo VI, da Carta Maior).

Em 1989, a Convenção n. 169 da Organização Internacional do Trabalho (OIT) estabeleceu significativos direitos aos Povos e Comunidades Tradicionais, como à autodeterminação e a consulta prévia, livre, informada e de boa-fé sempre que forem tomadas medidas legislativas ou administrativas que afetem diretamente essas comunidades e povos (OIT, 1989).

E, mais tarde, no ano de 1992, veio a Convenção sobre a Diversidade Biológica, fruto da ECO-92, uma Conferência das Nações Unidas sobre Meio Ambiente e Desenvolvimento, que aconteceu no Brasil.

A Convenção da Diversidade Biológica reconheceu a importância dos conhecimentos e saberes dos Povos e Comunidades Tradicionais. No preâmbulo, destaca a dependência dos recursos biológicos em relação as comunidades locais e populações indígenas com estilo de vida tradicionais. 
Já no artigo 8, alínea “j”, a Convenção da Diversidade Biológica estabelece a responsabilidade dos Estados em respeitar, preservar e manter o conhecimento, as inovações e práticas das comunidades locais e populações indígenas com estilo de vida tradicionais.

A Convenção da Diversidade Biológica nasceu com o viés economicista, visando a proteção dos recursos e repartição justa e equitativa de benefícios oriundos do uso desses recursos. No entanto, se tornou um acordo global sobre desenvolvimento sustentável, sobretudo reconhecendo a união entre os saberes tradicionais e a biodiversidade, ou seja, a sociobiodiversidade (BERTOLDI; BARON, 2014).

Tal Convenção foi assinada pelo Brasil em 1992, mas só no ano de 1998 foi promulgada, por meio do Decreto n. 2519/98. Porém, passou a vigorar no Brasil em 1994, porque foi nesse ano que o país a ratificou.

Ainda, é relevante falar da Convenção sobre a Proteção e Promoção da Diversidade das Expressões Culturais, promulgada em 2005, que no seu preâmbulo reconhece a importância dos conhecimentos tradicionais como fonte de riqueza material e imaterial e a necessidade de assegurar sua adequada proteção e promoção (BRASIL, 2005).

No Brasil, a Política Nacional de Desenvolvimento Sustentável dos Povos e Comunidades Tradicionais, aprovada pelo Decreto n. 6.040 de 2007, reconhece a importância da diversidade socioambiental brasileira e objetiva promover o desenvolvimento sustentável dos Povos e Comunidades Tradicionais, com foco na garantia de seus direitos, sobretudo ao território e a cultura, com respeito e valorização à sua identidade, suas formas de organização e suas instituições (BRASIL, 2007).

Sobre o tema, os Ministérios do Desenvolvimento Agrário, do Meio Ambiente e do Desenvolvimento Social e Combate à fome criaram em 2008 o Plano Nacional da Sociobiodiversidade, estabelecendo um conjunto de políticas, ações e projetos governamentais, as quais, dentre suas diretrizes estratégicas abrangem: promover o reconhecimento do direito dos povos indígenas, quilombolas, comunidades tradicionais e agricultores familiares ao acesso aos recursos da biodiversidade e à repartição justa e equitativa de benefícios e promover a valorização e respeito da diversidade cultural e conhecimento tradicional (BRASIL, 2008). 
Tal plano traz como definição de sociobiodiversidade: "a relação entre bens e serviços gerados a partir de recursos naturais, voltados à formação de cadeias produtivas de interesse de povos e comunidades tradicionais e de agricultores familiares".

Nesse sentido, a biodiversidade ou diversidade biológica contempla três elementos: a diversidade de espécies da fauna, flora e micro-organismos, diversidade dos ecossistemas e diversidade genética. Somando-se a este conceito o conhecimento, saber ou memória coletiva dos Povos e Comunidades Tradicionais, temos a sociobiodiversidade.

Outros programas governamentais como o Programa Agrobiodiversidade, que é uma política pública na área de conservação, manejo e uso sustentável da agrobiodiversidade e o Programa de Apoio ao Ecoturismo e à Sustentabilidade Ambiental - ProEcotur, implementado pelo Ministério do Meio Ambiente em parceria com o Ministério do Turismo, que opera uma carteira de projetos voltada a promoção do turismo com base comunitária foram sendo implementados pelo Governo Federal afim de proteger a sociobiodiversidade.

No ano de 2015, por meio da Lei n. 13.123, foi criado o Marco Legal da Biodiversidade, que foi bastante criticado devido à ausência de participação dos Povos e Comunidades Tradicionais na sua construção e por ter viés economicista, desconsiderando o direito a consulta previsto na Convenção da Diversidade Biológica.

Atualmente não se sabe quanto ao prosseguimento das ações em razão de o novo governo que assumiu o Executivo não demonstrar interesse político em investimentos nesse setor.

\section{A BIODEMOCRACIA E OS DIREITOS DA SOCIOBIODIVERSIDADE}

Diante do agravamento dos problemas ambientais, como o aumento da poluição, extinção de espécies e desmatamento unido a importância dos Povos e Comunidades Tradicionais para a conservação da biodiversidade, tem-se uma urgente necessidade de se garantir os direitos da sociobiodiversidade (IRIGARAY; MARTINS, 2016).

Diante da relação de dominação do poder hegemônico eurocêntrico em detrimento da preservação da natureza e dos conhecimentos tradicionais, que ocasiona o desaparecimento de culturas inteiras e sérios prejuízos ao meio ambiente, é necessário pensar práticas que possam tentar reverter esse quadro. 
Nesse sentido, a biodemocracia considera a relação do ser humano com a natureza, atribuindo valor a todos os seres vivos e reconhecendo os direitos originários dos Povos e Comunidades Tradicionais, sobretudo aqueles relacionados aos conhecimentos, saberes e modos de exploração da biodiversidade (IRIGARAY; MARTINS, 2016).

Nesse ponto, a biodemocracia influencia a preservação da sociobiodiversidade com base na ecologia e na justiça como alternativa à dominação imperialista de destruição da sociobiodiversidade, trazendo um novo paradigma para tratar o assunto.

A biodemocracia pode ser um meio de garantir os direitos da sociobiodiversidade, assegurando o sustento das populações, a justiça social, estabilidade ecológica, valorização e preservação dos saberes tradicionais e conservação da biodiversidade (SHIVA, 2003).

A biodemocracia parte do pressuposto de se reconhecer todos os seres vivos, sendo uma "democracia ecológica", buscando enxergar a terra de forma integrativa, considerando as diversidades cultural, econômica, social e política. Portanto, a biodemocracia e a sociobiodiversidade se relacionam no sentido de que, a primeira é considerada alternativa de proteção dos direitos da última (ARAÚJO, 2013).

\section{OS POVOS E COMUNIDADES TRADICIONAIS E SEUS DIREITOS COMO PERTENCENTES A SOCIOBIODIVERSIDADE}

\subsection{QUEM SÃO OS POVOS E COMUNIDADES TRADICIONAIS?}

O Direito Moderno excluiu a natureza e os conhecimentos culturais ao não considera-los com bens jurídicos a serem tutelados. Considerou como bem jurídico apenas o que pudesse ser enquadrado como mercadoria capitalista, Na América Latina, sobretudo no Brasil, essa dinâmica foi ainda mais cruel com a desconsideração da rica sociobiodiversidade existente (SOUZA FILHO, 2016).

Até o século XX, pode-se dizer que esses povos lutavam pela sua sobrevivência, mas, a partir daí, surgiram como movimentos pela conquista de direitos. Sobre o assunto, durante 500 anos esses povos lutavam pela própria sobrevivência contra o sistema hegemônico. Somente no século XX surge uma unidade entre os povos para reivindicar seus direitos (SOUZA FILHO, 2016). 
O processo colonial no Brasil foi muito danoso para a natureza e para os Povos e Comunidades que aqui viviam e as que vieram viver. Nesse sentido, a Convenção 169 da OIT reconhece duas formas de organização social que, em tese, não integram o sistema capitalista hegemônico: os povos indígenas e os povos tribais (SOUZA FILHO, 2016).

Somente com as Constituições latino-americanas do final do século XX, os direitos da natureza e dos povos foram incorporados nos ordenamentos jurídicos, fruto de grandes lutas sociais, porém, enfrentam até hoje imensa dificuldade em sua efetivação, sobretudo devido ao jogo de poder e interesses econômicos e políticos (SOUZA FILHO, 2016).

No Brasil, a Constituição Federal de 1988 reconheceu os direitos dos povos indígenas, das comunidades quilombolas e tradicionais, em geral, sobretudo no artigo 216, já exposto anteriormente. No entanto, só no ano de 2007 os Povos e Comunidades Tradicionais passaram a integrar a agenda de políticas públicas, com o Decreto n. 6040, o qual define Povos, Comunidades Tradicionais e Territórios Tradicionais em seu artigo $3^{\text {o. }}$ :

\begin{abstract}
Art. $3^{\circ}$-Para os fins deste Decreto e do seu Anexo compreende-se por:
I - Povos e Comunidades Tradicionais: grupos culturalmente diferenciados e que se reconhecem como tais, que possuem formas próprias de organização social, que ocupam e usam territórios e recursos naturais como condição para sua reprodução cultural, social, religiosa, ancestral e econômica, utilizando conhecimentos, inovações e práticas gerados e transmitidos pela tradição;

II - Territórios Tradicionais: os espaços necessários à reprodução cultural, social e econômica dos povos e comunidades tradicionais, sejam eles utilizados de forma permanente ou temporária, observado, no que diz respeito aos povos indígenas e quilombolas, respectivamente, o que dispõem os arts. 231 da Constituição e 68 do Ato das Disposições Constitucionais Transitórias e demais regulamentações (...)
\end{abstract}

Nesse sentido, os Povos e Comunidades Tradicionais são grupos com características comuns, relacionadas a simbologia, mitos e rituais associados a caça, pesca e atividades extrativistas. Outras características são a auto identificação, identidade e cultura próprias, ocupação de um determinado território por gerações, mesmo que alguns membros se desloquem para outros lugares.

\title{
4.2 OS DIREITOS E DESAFIOS DOS POVOS E COMUNIDADES TRADICIONAIS FRENTE AO MODELO DE ESTADO CAPITALISTA HEGEMÔNICO
}


Os direitos dos Povos e Comunidades Tradicionais sempre foram violados e silenciados pelo sistema capitalista hegemônico. Existe uma estratégia de violação de direitos e invisibilização desses povos (TARREGA; FRANCO, 2016).

A Constituição Federal de 1988, no seu artigo 216 garante o direito e a proteção do patrimônio cultural dos diferentes grupos formadores da sociedade brasileira, ou seja, dos Povos e Comunidades Tradicionais. A Carta Magna também estabelece que a expansão da propriedade privada da terra tem que respeitar a territorialidade desses povos (TÁRREGA; RIBEIRO, 2017).

Os direitos ao território, a identidade e a cultura dos Povos e Comunidades Tradicionais também são reconhecidos pela Constituição Federal de 1988. No entanto, apesar de reconhecer os direitos coletivos, da natureza, dos Povos Indígenas, quilombolas e das Comunidades Tradicionais em geral, a Constituição Federal de 1988 manteve o reconhecimento dos direitos de propriedade individual, principalmente da terra, o que fomenta diversos conflitos na atualidade de direitos individuais versus direitos coletivos (SOUZA FILHO, 2016).

Conforme afirmado por Tárrega e Ribeiro (2017, p. 252): "Há inúmeras denúncias de que a expansão econômica dos grandes mercados, notadamente o neoextrativismo, a mineração e o agronegócio, tem dificultado o respeito aos direitos dos povos tradicionais".

Nessa toada, existe um jogo de poder político e econômico por parte dos Poderes Legislativo, Executivo e Judiciário unidos aos interesses dos latifundiários e grandes empresas que possuem interesses econômicos nos territórios tradicionalmente ocupados, seguindo a lógica capitalista. Nesse sentido, inúmeros são os desafios dos Povos e Comunidades Tradicionais na efetivação de seus direitos.

\subsection{A RELAÇÃO DOS POVOS E COMUNIDADES TRADICIONAIS COM A BIODIVERSIDADE (A SOCIOBIODIVERSIDADE)}

Grande parte das florestas brasileiras estão nos territórios tradicionalmente ocupados pelos Povos e Comunidades Tradicionais. E são nessas áreas que se encontram a cobertura vegetal e rios mais preservados. Mesmo com a grande concentração de terras nas mãos de latifundiários, são nos territórios tradicionais que encontramos maior respeito à biodiversidade (ALMEIDA, 2010). 
São as terras indígenas, das comunidades quilombolas, dos seringueiros, das quebradeiras de coco babaçu, das castanheiras, dos ribeirinhos, das comunidades de faxinais e de fundos de pasto, dentre outras (ALMEIDA, 2010).

Nesse ponto, é urgente a proteção dos direitos dos Povos e Comunidades Tradicionais aliado a proteção da biodiversidade, ou seja, garantir a proteção da sociobiodiversidade.

Nessa toada emerge a necessidade de proteção aos direitos da sociobiodiversidade sob uma nova perspectiva, a da biodemocracia.

\section{5 (RE) EXISTÊNCIAS E (CO) EXISTÊNCIAS DOS POVOS E COMUNIDADES TRADICIONAIS NA PERSPECTIVA DA BIODEMOCRACIA}

O debate sobre os direitos da sociobiodiversidade nos leva a refletir sobre a importância de se garantir os direitos dos Povos e Comunidades Tradicionais. No entanto, o modelo de Estado Moderno que vigora na contemporaneidade, apesar de reconhecer direitos desses povos e comunidades, mantém o modelo de proteção da propriedade privada e de nação única.

Isso, aliado ao jogo de poder político e econômico e aos interesses dos donos do capital, na maioria das vezes latifundiários interessados nos territórios tradicionais, torna-se um entrave a efetivação dos direitos desses povos e comunidades de forma plena.

O Estado Moderno não permite o reconhecimento dos diversos povos e culturas, é centrado, unitário, organizado de forma institucional, baseado na liberdade individual e igualdade para garantir a propriedade privada (DANTAS, 2017).

O modelo atual de Estado no Brasil segue o raciocínio e a ideologia de homogeneidade, fundamentado na Constituição Federal de 1988, não se admitindo a formação multiétnica, só reconhecendo o povo como único e não como plural (DANTAS, 2017).

O que se pode extrair desse ensinamento é que a Constituição Federal de 1988, apesar de ter sido importante para a luta dos Povos e Comunidades Tradicionais, sobretudo ao reconhecer o direito a proteção da cultura e identidade, manteve o mesmo modelo de Estado 
capitalista hegemônico eurocêntrico, mantendo uma ideologia dominante de povo único, o povo brasileiro. Quando na verdade o Brasil é um país de diversos povos.

Além dos conflitos por território enfrentados pelos Povos e Comunidades Tradicionais, existe uma estratégia de dominação colonizadora para promover o desaparecimento dos conhecimentos e saberes tradicionais, e até mesmo de sua identidade, por meio de sua interação com o saber ocidental dominante. Por meio da negação de sua existência, a sua invisibilização, afirmação de que não existe ou não é legítimo. Essa prática do sistema capitalista hegemônico visa destruir a sociobiodiversidade (SHIVA, 2003).

No entanto, os Povos e Comunidades Tradicionais resistem, no sentido de não aceitarem a homogeneização proposta pelo modelo de Estado capitalista hegemônico eurocêntrico e de afirmarem sua existência e identidade frente a tentativa de sua invisibilização.

Conforme afirma Shiva (2003, p. 8): “A diversidade é uma alternativa à monocultura, à homogeneidade e à uniformidade. Viver a diversidade na natureza corresponde a viver a diversidade de culturas. As diversidades natural e cultural são fontes de riqueza e alternativas".

Nesse sentido, a (re) existência pode ser compreendida como um processo contínuo de permanência por meio de ações políticas, econômicas, sociais e culturais com o fim de reafirmar a existência dos Povos e Comunidades Tradicionais e seus diferentes elementos socioculturais. É uma forma de continuar a existir por meio da consolidação ou enraizamento de sua cultura, identidade e saber (GONÇALVES, 2001).

Já a (co) existência pode ser entendida como a possibilidade de existência da "civilização" e dos Povos e Comunidades Tradicionais simultaneamente e que a existência de um não depende da destruição do outro, desde que haja respeito aos direitos e ao modo de viver de cada um (SILVA, 2017).

Nesse sentido, a biodemocracia visa a construção de uma nova ordem. Mas, para isso, é necessário descontruir a ideia do Estado capitalista hegemônico atual e iniciar uma fase de conscientização para a desconstrução da colonialidade e abertura para o debate socioambiental, que se baseie na diversidade e sustentabilidade por meio de uma democracia ecológica (SOBRINHO; PIRES, 2018).

Essa pode ser uma alternativa para efetivar os direitos dos Povos e Comunidades Tradicionais e fortalecer a (re) existência e a (co) existência desses povos e comunidades. 


\section{CONCLUSÃO}

Enfim, diante dos problemas ambientais emergentes e da importância dos Povos e Comunidades Tradicionais para a manutenção da biodiversidade, é importante a discussão sobre a proteção dos direitos da sociobiodiversidade.

A Sociobiodiversidade pode ser compreendida como a junção dos três elementos essenciais da biodiversidade ou diversidade biológica, quais sejam, a diversidade de espécies da fauna, flora e micro-organismos, diversidade dos ecossistemas e diversidade genética com um quarto elemento, por sua vez cultural, que são o saber ou memória coletiva dos Povos e Comunidades Tradicionais.

Os Povos e Comunidades Tradicionais são grupos com características comuns, relacionadas a simbologia, mitos e rituais associados a caça, pesca e atividades extrativistas. Outras características são a auto identificação, identidade e cultura próprias, além da ocupação de um determinado território por gerações.

Vislumbra-se que, o modelo de Estado Moderno que vigora na contemporaneidade, apesar de reconhecer direitos desses povos e comunidades, mantém o modelo de proteção da propriedade privada e de nação única.

A Constituição Federal de 1988, apesar de ter sido importante para a luta dos Povos e Comunidades Tradicionais, sobretudo ao reconhecer o direito a proteção da cultura e identidade, manteve o mesmo modelo de Estado capitalista hegemônico eurocêntrico, mantendo uma ideologia dominante de povo único, o povo brasileiro. Quando na verdade o Brasil é um país de diversos povos.

Além disso, existe um jogo de poder político e econômico por parte dos Poderes Legislativo, Executivo e Judiciário unidos aos interesses dos latifundiários e grandes empresas que possuem interesses econômicos nos territórios tradicionalmente ocupados, tudo isso dificulta a efetivação dos direitos desses povos e comunidades.

Portanto, é urgente a proteção dos direitos dos Povos e Comunidades Tradicionais aliado a proteção da biodiversidade, ou seja, garantir a proteção da sociobiodiversidade.

Nesse sentido, a (re) existência pode ser compreendida como um processo contínuo de permanência por meio de ações políticas, econômicas, sociais e culturais com o fim de 
reafirmar a existência dos Povos e Comunidades Tradicionais e seus diferentes elementos socioculturais.

Já a (co) existência pode ser entendida como a possibilidade de existência da "civilização" e dos Povos e Comunidades Tradicionais simultaneamente e que a existência de um não depende da destruição do outro, desde que haja respeito aos direitos e ao modo de viver de cada um.

Uma alternativa para a efetivação dos direitos da sociobiodiversidade e a (re) existência e (co) existência desses povos é a biodemocracia, a qual visa a construção de uma nova ordem. Mas, para isso, é necessário descontruir a ideia do Estado capitalista hegemônico atual e iniciar uma fase de conscientização para a desconstrução da colonialidade e abertura para o debate socioambiental, que se baseie na diversidade e sustentabilidade por meio de uma democracia ecológica

A biodemocracia considera a relação do ser humano com a natureza, atribuindo valor a todos os seres vivos e reconhecendo os direitos originários dos Povos e Comunidades Tradicionais, sobretudo aqueles relacionados aos conhecimentos, saberes e modos de exploração da biodiversidade.

Influencia a preservação da sociobiodiversidade com base na ecologia e na justiça como alternativa à dominação imperialista de destruição da sociobiodiversidade, trazendo um novo paradigma para tratar o assunto.

Nesse sentido, a biodemocracia pode ser um meio de garantir os direitos da sociobiodiversidade, assegurando o sustento das populações, a justiça social, estabilidade ecológica, valorização e preservação dos saberes tradicionais e conservação da biodiversidade, tendo importante papel na luta pela (re) existência e (co) existência dos Povos e Comunidades Tradicionais. 


\section{REFERÊNCIAS}

ALMEIDA, A. W. B. Agroestratégias e Desterritorialização: Direitos Territoriais e Étnicos na Mira dos Estrategistas dos Agronegócios. In ALMEIDA, A. W. B (et al). Capitalismo Globalizado e Recursos Territoriais: Fronteiras de Acumulação no Brasil Contemporâneo. Rio Janeiro: Lamparina, 2010, p.101-146.

ARAUJO, L. E. B.. O Direito da Sociobiodiversidade. DIREITOS EMERGENTES NA SOCIEDADE GOLBAL- Anuário do Programa de Pós-Graduação em Direito da UFSM. Organizadores: Jerônimo Siqueira Tybusch, Luiz Ernani Bonesso de Araújo e Rosane Leal da Silva. Ijuí. 2013.

BERTOLDI, M. R.; BARON, L.. Solidariedade entre a Sociobiodiversidade e o Desenvolvimento Sustentável. Florianópolis: CONPEDI, 2014.

BRASIL. Constituição Federal de 1988, de 05 de outubro de 1988. Diário Oficial da República Federativa do Brasil, Poder Legislativo, Brasília, DF, 05 out. 1988. Disponível em: http://www.planalto.gov.br/ccivil_03/constituicao/constituicaocompilado.htm. Acesso em: 01 jun. 2018.

BRASIL. Lei n. 13.123, de 20 de maio de 2015. Poder Legislativo, Brasília, DF, 20 mai. 2015. Disponível em: http://www.planalto.gov.br/CCIVIL 03/ Ato20152018/2015/Lei/L13123.htm. Acesso em: 20 fev. 2019.

BRASIL. Decreto n. 6040, de 07 de fevereiro de 2007. Institui a Política Nacional de Desenvolvimento Sustentável dos Povos e Comunidades Tradicionais. Poder Executivo, Brasília, DF, 07 fev. 2017. Disponível em: http://www.planalto.gov.br/ccivil 03/ Ato20072010/2007/Decreto/D6040.htm. Acesso em: 20 fev. 2019.

BRASIL. Decreto n. 2.519, de 16 de março de 1998. Promulga a Convenção da Diversidade Biológica. Poder Executivo, Brasília, DF, 16 mar. 1998. Disponível em: http://www.planalto.gov.br/ccivil_03/decreto/D2519.htm. Acesso em: 20 fev. 2019.

BRASIL. Decreto n. 6.177, de 01 de agosto de 2007. Promulga a Convenção sobre a Proteção e Promoção da Diversidade das Expressões Culturais. Poder Executivo, Brasília, DF, 01 agos. 2007. Disponível em: http://www.planalto.gov.br/ccivil_03/_ato20072010/2007/decreto/d6177.htm. Acesso em: 20 fev. 2019.

BRASIL. Relatório de Monitoramento de Cobertura do Solo e Uso da Terra (IBGE). Disponível em: https://www.ibge.gov.br/geociencias-novoportal/informacoesambientais/cobertura-e-uso-da-terra/15831-cobertura-e-uso-da-terra-do-brasil.html $=\& \mathrm{t}=\mathrm{O}-$ que-e. Acesso em: 22 fev. 2019.

CAVAlHEIRO, L. N.; ARAUJO, L. E. B.. Direito Ambiental e as Diversidades Natural e Cultural no Brasil: Direitos da Sociobiodiversidade e Sustentabilidade na Constituição Federal. Revista da Faculdade de Direito da Universidade Federal de Goiás. Goiânia-GO, v. 41, n. 1, p. 125-141, jan/jun. 2017. 
CONVENÇÃO n. 169, 1989, Genebra, Suíça. Conferência Geral da Organização Internacional do Trabalho, 1989.

CONVENÇÃO SOBRE DIVERSIDADE BIOLÓGICA, Rio de Janeiro, Brasil. Conferência das Nações Unidas sobre Meio Ambiente e Desenvolvimento, 1992. Disponível em: http://www.mma.gov.br/biodiversidade/conven\%C3\%A7\%C3\%A3o-da-diversidadebiol\%C3\%B3gica.html. Acesso em: 07 out. 2018.

DANTAS, F. A. C.. Entre a Nação Imaginada e o Estado Plurinacional: o Reconhecimento dos Direitos Indígenas no Novo Constitucionalismo Latino-Americano. In: AVRITZER, L., et al (Orgs.). O Constitucionalismo Democrático Latino-Americano em Debate: Soberania, Separação de Poderes e Sistema de Direitos. Belo Horizonte-MG: Autêntica, 2017, p.213-230.

GONÇALVES, C.W. P.. Amazônia, Amazônias. São Paulo: Editora Contexto, 2001.

GUSTIN, M. B. S; DIAS, M. T. F. (Re) Pensando a Pesquisa Jurídica. Minas Gerais: Del Rey, 2010.

IRIGARAY, M. C.; MARTINS, E, J,. Sociobiodiversidade e Biodemocracia: Uma (Re) Aproximação do Homem com a Natureza. Revista de Direito Ambiental e Socioambientalismo. Brasília-DF, v. 2, n. 1, p. 170-189, jan/jun. 2016.

SANTILLI, J. Socioambientalismo e Novos Direitos: proteção jurídica à diversidade biológica e cultural. São Paulo: Editora Peirópolis, Instituto Socioambiental e Instituto de Educação do Brasil, 2005.

SHIVA, V. Monoculturas da Mente: Perspectivas da Biodiversidade e da Biotecnologia. São Paulo: Gaia, 2003.

SANTOS, B. S.. Refundación del Estado en América Latina: Perspectivas desde una epistemología del Sur. Peru: Instituto Internacional de Derecho y Sociedad, 2010.

SOBRINHO, L. L. P.; PIRES, N. S. S.. Biodemocracia: uma Leitura a partir da Decolonialidade do Saber. Revista Direito Ambiental e Sociedade. Caxias do Sul-RS, v. 8, n. 1, p. 7-23, 2018.

SOUZA FILHO, C. F. M.. O Retorno da Natureza e dos Povos com as Constituições Latino-Americanas. In: TÁRREGA, M. C. V. B., et al. Estados e Povos na América Latina Plural. Goiânia-GO: Editora PUC GOIÁS, 2016, p. 23-76.

SILVA, L. A. L. Consulta Prévia e a Livre Determinação dos Povos Indígenas e Tribais na América Latina: Re-existir para Co-existir. 2017. 324 f. Tese (Doutorado em Direito Socioambiental e Sustentabilidade - Faculdade de Direito, Pontifícia Universidade Católica do Paraná - PUC, Paraná, 2017. 
TÁrReGA, M. C. V. B.; RIBEIRO, L. G. G.. (Orgs.). Novas Perspectivas do Direito: Diálogos ou Disjunções entre o Direito Público e o Direito Privado. Florianópolis: CONPEDI, 2017.

TÁRREGA, M. C. V. B.; FRANCO, R. D.. A Odisseia Jurídica para a Proteção das Territorialidades: o Território Kalunga. In: TÁRREGA, M. C. V. B.; SOUZA FILHO, C. F. M.; WOLKMER, A. C. (Orgs.). Os Direitos Territoriais Quilombolas Além do Marco Temporal. Goiânia-GO: Editora PUC GOIÁS, 2016, p. 125-147.

VIEIRA, R. S.. A Construção do Direito Ambiental e da Sustentabilidade: Reflexões a Partir da Conjuntura da Conferência das Nações Unidas sobre Desenvolvimento Sustentável (Rio+20). In: PRIEUR, M.; SILVA, J. A. T.. Instrumentos Jurídicos para a Implementação do Desenvolvimento Sustentável. Goiânia-GO: Editora PUC GOIÁS, 2012, p. 355-390 